\title{
Revisión sistemátia: la amoxicilina y el cotrimoxazol constituyen la estrategia más costo-efectiva en el tratamiento de la rinosinusitis aguda bacteriana
}

Diagnosis and Treatment of Acute Bacterial Rhinosinusitis Agency for Health Care Policy and Research (AHCPR).U.S. Departament of health and human Services. Public Health service. Pub. No 99-E015. March 1999.

\section{Objetivo}

Evaluar la evidencia disponible relacionada con el diagnóstico y tratamiento de la rinosinusitis aguda bacteriana (RAB) adquirida en la comunidad, tanto en niños como en adultos.

\section{Fuente y selección de datos}

La revisión estuvo a cargo de New England Medical Center Evidence-Based Practice Center (EPC), EE.UU. Incluyó artículos en inglés y en otros idiomas del MEDLINE, entre 1966 y Mayo de 1998.

\section{Extracción de datos}

El EPC trabajó en colaboración con un panel de expertos de las principales asociaciones médicas académicas.

La revisión bibliográfica se realizó en base a las siguientes preguntas: 1) ¿Cuál es la prevalencia de infección bacteriana en los pacientes con rinosinusitis aguda (RA) evaluada por médicos de atención primaria vs. especialistas?. 2) ¿Cuál es el valor diagnóstico de las características clínicas y estudios de imágenes para su identificación? 3) ¿Los antibióticos son efectivos para resolver los síntomas y prever complicaciones? 4) ¿Son mejores que el placebo? 5) ¿Sirven otros tratamientos: descongestivos, corticoides, antihistamínicos, drenaje y lavado de senos? ¿Cómo se comparan con los antibióticos? Se incluyeron estudios prospectivos que compararon dos o más test diagnósticos para evaluar el rendimiento de los mismos y ensayos clínicos controlados aleatorizados (ECCA) para evaluar la eficacia del tratamiento. Realizaron análisis de costo efectividad comparando distintas estrategias terapéuticas.

\section{Resultados}

La calidad metodológica de los estudios reportados en general fue pobre. Catorce de 48 estudios comparativos de test diagnósticos y 30 de 74 ECCAs de antibióticos, reunieron los criterios de inclusión. De los estudios en niños solo 2 reunieron los criterios. Según los datos de la encuesta nacional ambulatoria de EE.UU la prevalencia de sinusitis aguda se incrementó del $0.2 \%$ en 1990 a $0.4 \%$ en 1995. En los consultorios de clínica médica general un $38 \%$ de los pacientes adultos con síntomas de sinusitis pudieron ser RAB, y esta probabilidad fue mayor para los otorrinolaringólogos (50 al $80 \%$ ). Entre el 6 y $18 \%$ de los chicos con síntomas del tracto respiratorio superior presentaron RAB. Se encontró poca evidencia para sugerir que los criterios clínicos pudieran tener similar precisión diagnóstica que la radiografía de senos. A pesar de no constituir una práctica de rutina dado que es un método invasivo y costoso la punción de senos y cultivo es el diagnóstico de certeza. La radiografía de senos presentó una sensibilidad del $76 \%$ y especificidad del $79 \%$. No existieron estudios contundentes que evaluaran tanto la RMN o TAC. La mayoría de los ECCAs incluidos tuvieron un período de seguimiento corto y no evaluaron recaídas y complicaciones como meningitis, absceso de cerebro y celulitis periorbitaria. Los antibióticos fueron significativamente más efectivos que el placebo en el tratamiento de la RAB, reduciendo el tiempo de recuperación y el riesgo de fracaso clínico, si bien dos tercios de los que recibieron placebo también se recuperaron. La actual evidencia afirma que la amoxicilina y el cotrimoxazol (trimetroprima-sulfametoxazol, [TMS]) son tan eficaces como los nuevos y más costosos antibióticos, no justificándose el uso de estos últimos. Si bien muchos ECCAs con tratamiento antibiótico incluyeron tratamientos auxiliares, no fue posible realizar un meta-análisis dado los diferentes tratamientos comparados, los criterios diagnósticos y los resultados medidos. No se puede responder claramente acerca de su rol en el manejo.

\section{Conclusión}

De acuerdo con la evidencia resulta razonable dar pautas de alarma durante los primeros 7 a 10 días antes de prescribir antibióticos ya que la mayoría resuelven sin su uso y las complicaciones serias son raras. Finalmente la evidencia confirma el uso de la amoxicilina o TMS-SMZ como la terapia antibiótica de elección.

Fuente de financiamiento: AHCPR, EE.UU.

\section{Comentario}

En el presente trabajo se realizó una amplia y completa revisión sistemática de los trabajos publicados en relación al diagnóstico y tratamiento de la RAB adquirida en la comunidad, tanto en niños como en adultos. Es importante recalcar que la calidad metodológica de los trabajos publicados fue pobre. Si bien los mismos fueron numerosos, otra característica común en la mayoría de estos fue el tiempo de duración, el cual en general no era lo suficientemente prolongado como para hacer una evaluación más contundente en cuanto a las fallas terapéuticas, recaídas y presencia de complicaciones de la enfermedad o efectos indeseables de los tratamientos. Es de destacar la evidencia poco contundente hallada en relación a la precisión diagnóstica tanto de los datos semiológicos comparados con la radiografía de senos, así como también entre los demás estudios diagnósticos evaluados.

Un dato importante y notorio es la gran diferencia existente en la presunción diagnóstica entre los médicos generales y los otorrinolaringólogos, ya que se observó que para los primeros solo un $38 \%$ de los pacientes adultos con síntomas pudieron ser RAB contra un 50 a $80 \%$ según los especialistas. Esto nos hace pensar en la posibilidad de un bajo nivel de alarma de unos o un sobrediag- nóstico por parte de otros. Por lo tanto, creemos imprescindible trabajar en este punto en pro de los pacientes y consensuar estrategias terapéuticas más costo efectivas.

Los estudios coinciden en que la amoxicilina oTMS son tan eficaces como los nuevos antibióticos disponibles hoy en el mercado para el tratamiento de la RAB, siendo estos últimos de mayor costo con lo cual los primeros siguen siendo considerados drogas de elección. Trabajos recientes no incluidos en esta revisión reafirman que la amoxicilina y el TMS constituyen la estrategia más costo-efectiva, ${ }^{1}$ que la presencia de síntomas clínicos leves compatibles con RA no son predictores de la existencia de bacterias² y que en los casos cuya duración es menor a 7 días 3 la conducta más apropiada es la recomendación de pautas de alarma, ya que en su mayoría resuelven sin el uso de terapias antibióticas.3,4

Este trabajo abre las puertas a futuras investigaciones que se deberían hacer con diseños apropiados (selección de población, criterios clínicos, métodos auxiliares de diagnóstico, etc.), para obtener así respuestas más contundentes a aquellos interrogantes en los que no se encontró una suficiente evidencia.

\section{Dr. Javier Chiarpenello [ Jefe del Centro de Salud No 29 Hospital Provincial de Rosario. Médico de Familia Construir Salud. ]}

\author{
Referencias \\ 1. Benninger Ms, et al. Diagnosis and tratment of uncomplicated acute bacterial rhinosinusitis: summary of the Agency for Health Care Policy and Research Evidence- Based Report. Oto- \\ laryngol Headneck Surg 2000; 122: 1-7. \\ 2. Ricchetti A., et.al. Symptoms and clinical and radiological signs predicting the bacterial rigin of acute rhinosinusitis. Schweiz Med Wochenschr 2000; 125: 275-295. \\ 3. Hickner JM et.al. Principles of appropriate antiobiotic use for acute rhinosinusitis in adults. Background. Ann Emerg Med 2001; 37: 703-10. \\ 4. Osguthorpe J.D. Adult rhinosinusitis: diagnosis and management. American Family Physician 2001; 16: 69-76.
}

